\title{
Preparation and Characterization of Bimetallic Oxides of Chromium and Titanium
}

\author{
Soofin Cheng ${ }^{1}$ and Sheng-Yuan Cheng \\ Department of Chemistry, National Taiwan University, Taipei, Taiwan, Republic of China
}

Received October 19, 1988; revised February 22, 1989

\begin{abstract}
Mixed oxides of $\mathrm{Cr}$ (III) and Ti(IV) were prepared by the hydrothermal method in basic solutions $(\mathrm{pH}>12)$. With $\mathrm{NaOH}$ as base, the resultant materials had a layered structure. After exchange with $\mathrm{NH}_{4}^{+}$ions and calcination at $623 \mathrm{~K}$, the layered structure was converted to the anatase phase. When the calcination temperature was raised to $723 \mathrm{~K}$ and higher, a portion of the anatase phase was converted to the rutile phase for samples of high $\mathrm{Cr}(\mathrm{III})$ content. The latter also contained a small amount of $\mathrm{Cr}_{2} \mathrm{O}_{3}$ structure. When the 2-propanol decomposition reaction was carried out, the mixed oxides demonstrated both acidic and basic sites on the surfaces. Furthermore, both Brønsted and Lewis acid sites were found on the surface of the bimetallic oxides, based on IR spectra of the adsorbed pyridine. The Bronsted acid sites were identified as $\mathrm{CrO}-\mathrm{H}$ groups. When the bimetallic oxides were used as catalysts in oxidative dehydrogenation of ethane, activity was found to be a function of $\mathrm{Cr}$ content. The $\mathrm{Cr}-\mathrm{O}$ species were proposed to be the active sites for formation of both ethylene and $\mathrm{CO}_{2}$. Titanium served as a diluent. 1990 Academic Press, Inc.
\end{abstract}

\section{INTRODUCTION}

Oxides of silicon and aluminum are wellknown acid catalysts because of their capability in proton transfer and are widely used as catalysts in modern chemical industry. On the other hand, oxides of transition and post-transition metal elements are widely used in redox reactions because of their ability to take part in the exchange of electrons. In addition, highly dispersed metallic catalysts are usually supported over metal oxides to expose their effective surface areas. Typical catalyst supports in common use are $\mathrm{Al}_{2} \mathrm{O}_{3}, \mathrm{SiO}_{2}$, zeolite, and active carbon. In the 1970s a $\mathrm{TiO}_{2}$-based catalyst was first applied commercially in air pollution control equipment and became the subject of many scientific studies. Because $\mathrm{TiO}_{2}$ is easily reduced to form various stoichiometric and nonstoichiometric lower oxides, some distinguishing catalytic properties are expected when it is used as catalyst support. Indeed, the so-called strong metalsupport interaction (SMSI) was first re-

'To whom correspondence should be addressed. ported for noble metals supported on $\mathrm{TiO}_{2}$ (1). The $\mathrm{TiO}_{2}$-based catalyst was found to be the best catalyst for the selective catalytic reduction of $\mathrm{NO}_{x}$ with $\mathrm{NH}_{3}(2)$, and for partial oxidation of benzene to maleic anhydride (3).

Compared to commonly available $\mathrm{Al}_{2} \mathrm{O}_{3}$ and $\mathrm{SiO}_{2}$, titania has relatively low acidity and very few acidic sites on the surface (4). To improve the acidity, Shibata et al. (5) synthesized a series of binary metal oxides containing titanium by the coprecipitation method. The resultant oxides were found to show higher acid strength than each component oxide. Tanabe et al. (6) proposed a hypothesis to explain the formation of those acid sites; however, the materials themselves were not well characterized due to the amorphous nature of the solids. Since substitution with cations of lower oxidation states is expected to generate Brønsted acid sites, a series of titanium oxides doped with $\mathrm{Cr}(\mathrm{III})$ have been prepared in this experiment. For the purpose of correlating catalytic behavior to structure, the bimetallic oxides were synthesized by the coprecipitation method followed by hydro- 
thermal treatment to obtain crystalline materials. The technique used has been widely applied to prepare ZSM-like molecular sieves (7). A structure of high thermal stability was expected to be prepared by this technique. The acid/base properties of the resultant materials were characterized by infrared spectroscopy, temperature-programmed desorption (TPD) of ammonia, and 2-propanol decomposition reaction. Redox activity was examined by carrying out the oxidative dehydrogenation reaction of ethane.

\section{METHODS}

Reagents. Reagent-grade chemicals were used without further purification. $\mathrm{TiCl}_{4}$ was purchased from Merck. $\mathrm{Cr}\left(\mathrm{NO}_{3}\right) \cdot 9 \mathrm{H}_{2} \mathrm{O}$ was from Riedel-dehan. $\mathrm{NH}_{3}$ gas for the TPD experiment was dried by passing it through a three-stage cold trap at $263 \mathrm{~K}$ and a $\mathrm{NaOH}$ column at room temperature.

Catalyst. A $5 \mathrm{M} \mathrm{TiOCl}_{2}$ solution was prepared by dissolving $\mathrm{TiCl}_{4}$ in $1 \mathrm{~N} \mathrm{HCl}$ solution. It was used as the source of Ti(IV) in the following experiment. A powder of $\mathrm{Cr}\left(\mathrm{NO}_{3}\right)_{3} \cdot 9 \mathrm{H}_{2} \mathrm{O}$ was dissolved in $5 \mathrm{~N}$ $\mathrm{NaOH}$ solution. $\mathrm{TiOCl}_{2}$ solution was then added dropwise into the solution with vigorous stirring. The final $\mathrm{pH}$ of the solution was adjusted to be higher than 12 . The amorphous precipitate obtained was stirred for another $3 \mathrm{~h}$, followed by hydrothermal treatment in a sealed polypropylene bottle at $373 \mathrm{~K}$ for 7 days. The green solid was filtered and washed with deionized water until it was free of $\mathrm{Cl}^{-}$ions. The Brønsted acidic sites were formed by exchanging the incorporated $\mathrm{Na}^{+}$ions with an excess amount of $\mathrm{NH}_{4}^{+}$ions in $1 M \mathrm{NH}_{4} \mathrm{Cl}$ solution. The latter process was repeated three times at room temperature to achieve complete ion exchange, followed by washing and calcination at $623 \mathrm{~K}$. The $\mathrm{Cr}$ (III) content was varied from $1,5,9,15,20$, to $33 \%$ based on the starting $\mathrm{Cr} /(\mathrm{Ti}+\mathrm{Cr})$ mole ratios. Component oxides of $\mathrm{Ti}(\mathrm{IV})$ and $\mathrm{Cr}$ (III) were also prepared separately for comparison in similar procedures.
Apparatus. X-ray powder diffraction patterns were obtained using a Philips 1792 $\mathrm{X}$-ray diffractometer with $\mathrm{Cu} K \alpha$ radiation. Infrared spectra were obtained with a Perkin-Elmer 983 spectrometer and a Bomen DA 3.02 FT-IR spectrometer. The wafers used for examining the stretching modes of surface hydroxyl groups and chemisorbed pyridine were $0.01 \mathrm{~g} / \mathrm{cm}^{2}$ thick. Measurement of surface area of the catalysts was based on the physical adsorption of nitrogen at liquid $\mathrm{N}_{2}$ temperature using a volumetric system.

Procedures for TPD of $\mathrm{NH}_{3}$. A 0.2-g portion of the catalyst was packed in a U-shape stainless-steel reactor. A thermocouple well was fixed at the center of the catalyst bed to register the temperature in the reaction zone. The catalyst was preheated under a dried $\mathrm{N}_{2}$ atmosphere at $623 \mathrm{~K}$ for $1 \mathrm{~h}$. $\mathrm{NH}_{3}$ adsorption was carried out by passing dried $\mathrm{NH}_{3}$ gas through the catalyst bed for $10 \mathrm{~min}$ at room temperature, followed by purging with $\mathrm{N}_{2}$ gas for $30 \mathrm{~min}$ to drive excess $\mathrm{NH}_{3}$ out the system. The TPD profile was obtained by heating the catalyst bed to $873 \mathrm{~K}$ at a heating rate of $10^{\circ} \mathrm{K} / \mathrm{min}$, and the amount of $\mathrm{NH}_{3}$ desorbed was determined with a TCD detector.

Catalytic activity. The acid/base behavior of the catalysts was examined by carrying out the 2-propanol decomposition reaction in an ordinary plug-flow-type reactor at atmospheric pressure. Prior to the reaction, the calcined catalyst was reduced in a hydrogen stream at $623 \mathrm{~K}$ for $12 \mathrm{~h}$ to ensure that the catalyst had the chromium in the $\mathrm{Cr}$ (III) state. The rest of the procedures were same as those mentioned in a previous article (8). Redox activities of the catalysts were examined with the ethane oxidative dehydrogenation reaction in a plug-flowtype reactor at atmospheric pressure. The catalyst was preoxidized with air at reaction temperature, $723 \mathrm{~K}$, for $12 \mathrm{~h}$. A mixture of air/ethane in the ratio of $2 / 1$ was used as reactant. The products were separated with a Porapak S column. 

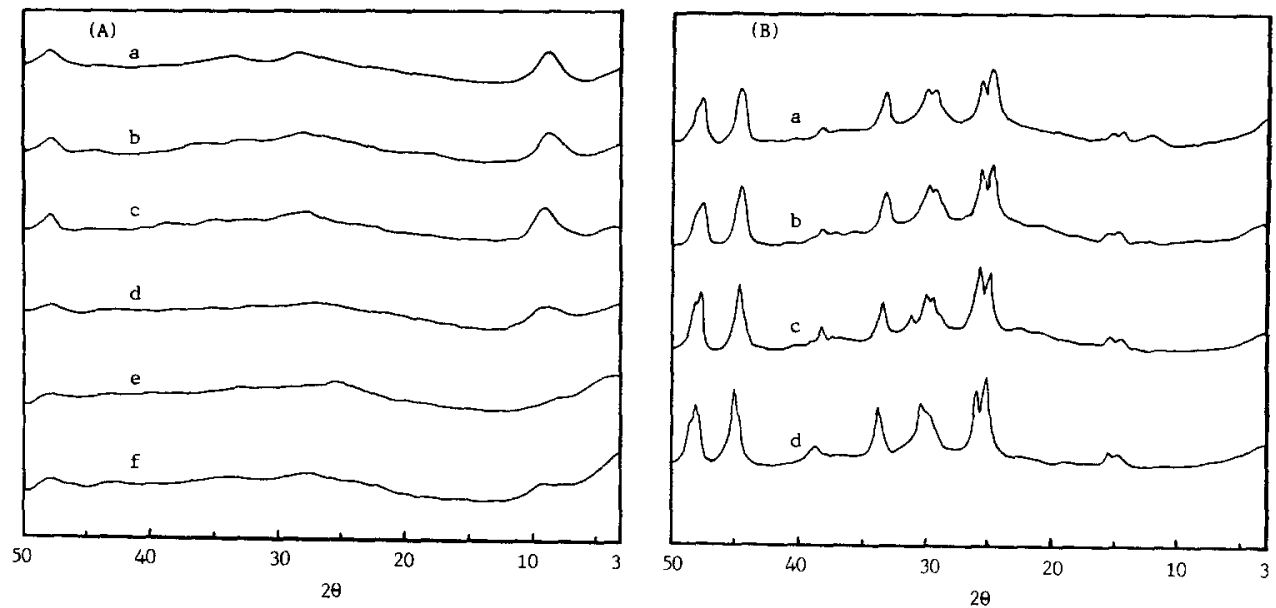

FIG. 1. XRD patterns of $\mathrm{Cr}-\mathrm{Ti}$ oxides before (A) and after (B) calcination at $823 \mathrm{~K} . \mathrm{Cr} /(\mathrm{Ti}+\mathrm{Cr})$ ratios varied as (a) $0 \%$, (b) $1 \%$, (c) $5 \%$, (d) $9 \%$, (e) $15 \%$, and (f) $20 \%$.

\section{RESULTS AND DISCUSSION}

X-ray powder diffraction patterns showed that the synthesized bimetallic oxides had rather low crystallinities (Fig. 1A). Broadening peaks were observed at $2 \theta=$ 25,37 , and $48^{\circ}$, in addition to a peak at $2 \theta=$ $9^{\circ}(d$ spacing $=9.8 \AA)$. The latter became more obvious as the $\mathrm{Cr}$ (III) content was decreased. After calcination at $823 \mathrm{~K}$ for $4 \mathrm{~h}$, the XRD patterns showed that crystalline phases were formed (Fig. 1B). The pattern

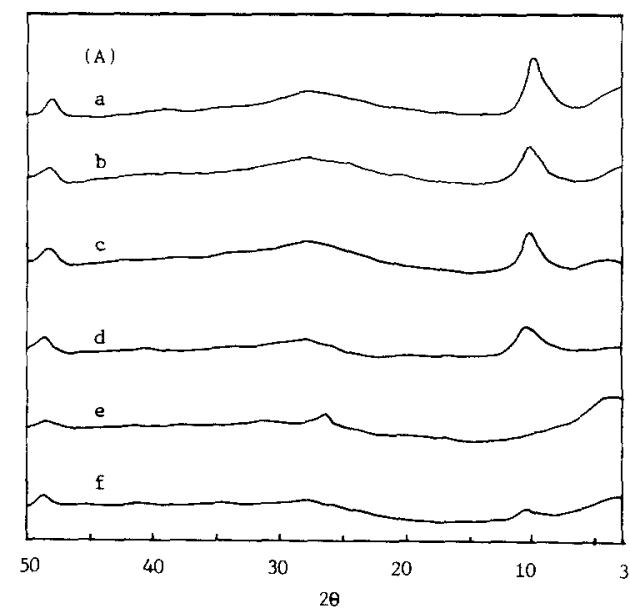

could be assigned to $\mathrm{Na}_{x} \mathrm{TiO}_{2}$ bronze (9), except for peaks at $2 \theta=25.2,37,37.8$, and $48^{\circ}$, which were assigned to the anatase form of the $\mathrm{TiO}_{2}$ phase.

Figure 2A shows the XRD patterns of samples after $\mathrm{NH}_{4}^{+} / \mathrm{Na}^{+}$ion exchange. The crystallinity was found to remain low. However, the peak originally observed at low diffraction angle had shifted from $2 \theta=$ $9^{\circ}$ to $2 \theta=10^{\circ}$. Accordingly, the $d$ spacing was found to shorten from 9.8 to $9.0 \AA$. After calcination at $623 \mathrm{~K}$, anatase was the

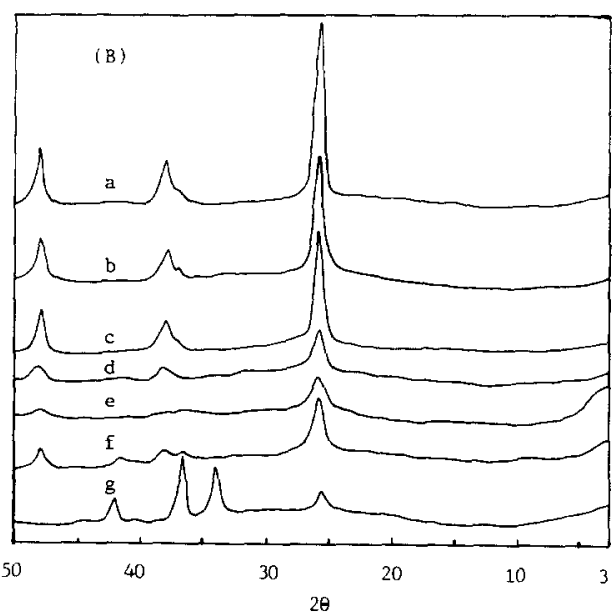

FIG. 2. XRD patterns of $\mathrm{Cr}-\mathrm{Ti}$ oxides after $\mathrm{NH}_{4}^{+} / \mathrm{Na}^{+}$ion exchange before (A) and after (B) calcination at $623 \mathrm{~K} . \mathrm{Cr} /(\mathrm{Ti}+\mathrm{Cr}$ ) ratios varied as (a) $0 \%$, (b) $1 \%$, (c) $5 \%$, (d) $9 \%$, (e) $15 \%$, (f) $20 \%$, and (g) $100 \%$. 

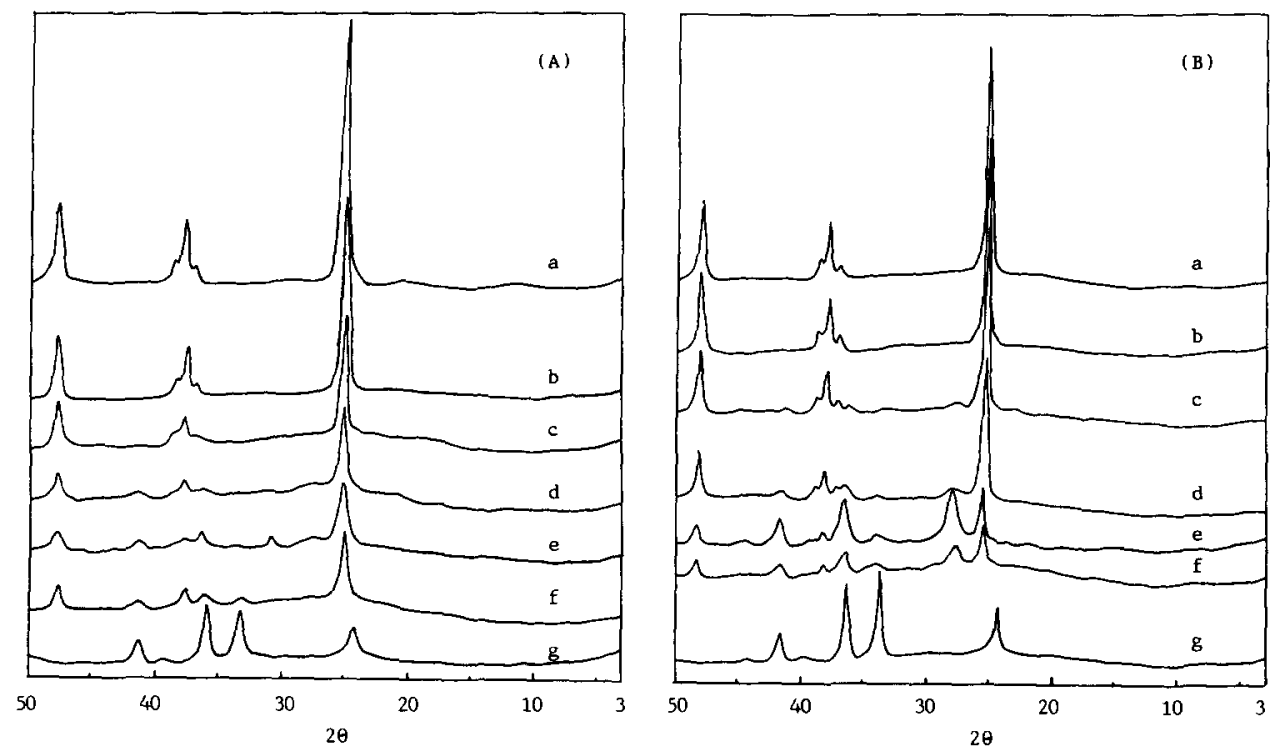

FIG, 3. XRD patterns of $\mathrm{Cr}-\mathrm{Ti}$ oxides after $\mathrm{NH}_{4}^{+} / \mathrm{Na}^{+}$ion exchange calcinated at (A) $723 \mathrm{~K}$ and (B) $943 \mathrm{~K} . \mathrm{Cr} /(\mathrm{Ti}+\mathrm{Cr})$ ratios varied as (a) $0 \%$, (b) $1 \%$, (c) $5 \%$, (d) $9 \%$, (e) $15 \%$, (f) $20 \%$, and (g) $100 \%$.

only crystalline phase observed for samples with a $\mathrm{Cr}$ (III) content lower than $15 \%$. As $\mathrm{Cr}$ (III) content was increased, a $\mathrm{Cr}_{2} \mathrm{O}_{3}$ phase was observed in addition to the anatase phase. Furthermore, the crystallinity obviously decreased as the $\mathrm{Cr}$ (III) content was increased. Calcining the samples at
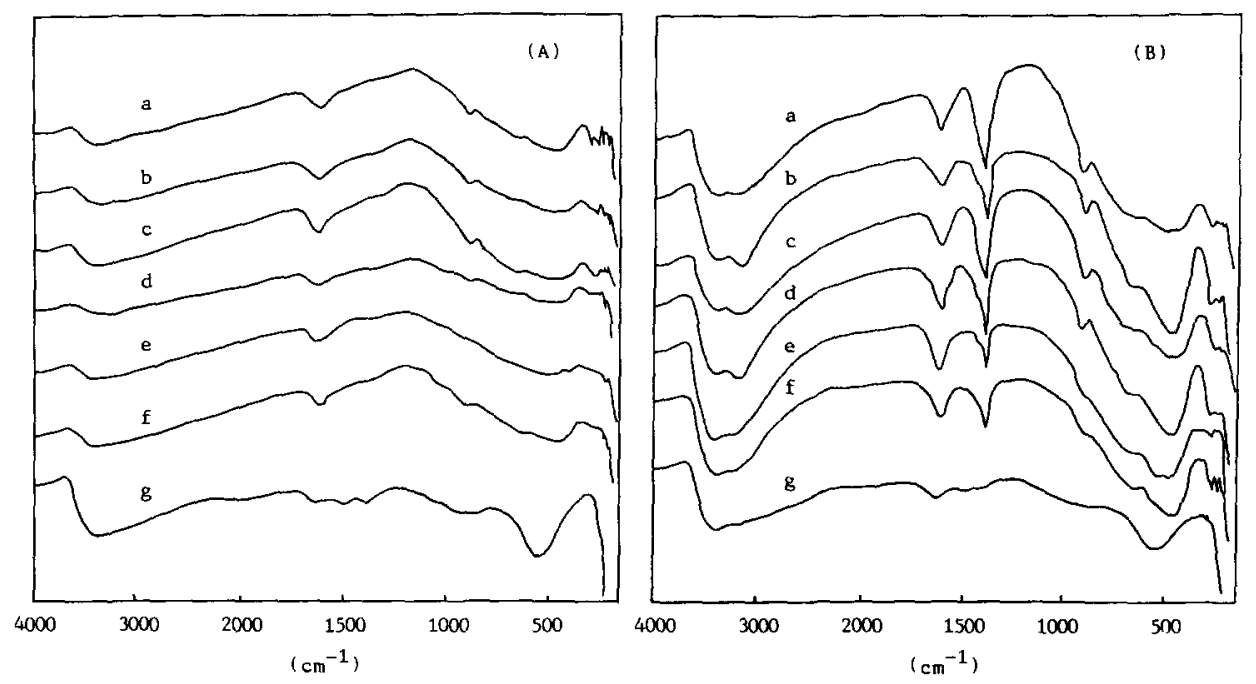

FIg. 4. IR spectra of $\mathrm{Cr}-\mathrm{Ti}$ oxides before (A) and after (B) $\mathrm{NH}_{4}^{+} / \mathrm{Na}^{+}$ion exchange. $\mathrm{Cr} /(\mathrm{Ti}+\mathrm{Cr})$ ratios varied as (a) $0 \%$, (b) $1 \%$, (c) $5 \%$, (d) $9 \%$, (e) $15 \%$, (f) $20 \%$, and (g) $100 \%$. temperatures higher than $723 \mathrm{~K}$ induced formation of the rutile form of $\mathrm{TiO}_{2}$ (Fig. 3). The latter was more obvious on samples with high $\mathrm{Cr}$ (III) content.

Figure 4 shows the infrared spectra of samples before and after $\mathrm{NH}_{4}^{+} / \mathrm{Na}^{+}$ion exchange. $\mathrm{NH}_{4}^{+}$incorporation was indicated 
by the additional peaks that appeared at ca. 1400 and $3300 \mathrm{~cm}^{-1}$ on the exchanged samples. These peaks, which corresponded to the bending and stretching modes of $\mathrm{N}-\mathrm{H}$ bonds, respectively, disappeared when the samples were calcined at $623 \mathrm{~K}$.

The shift of the X-ray diffraction peak at low angle with the $\mathrm{NH}_{4}^{+} / \mathrm{Na}^{+}$ion-exchange process indicated that the synthetic bimetallic oxides were layered structures. A series of layered titanates have been reported as inorganic ion exchangers (10). Izawa $e t$ al. (11) claimed that layered trititanate of the formula $\mathrm{Na}_{x} \mathrm{H}_{2}-x \mathrm{Ti}_{3} \mathrm{O}_{7}$ does not contain interlayer water and had interlayer distances that varied in the range 8.08-8.54 $\AA$. Since those are smaller than what we have obtained, the structure of trititanate is ruled out. The other possible layered structure is tetratitanate. Sasaki et al. (12) studied the $\mathrm{Na}^{+} / \mathrm{H}^{+}$ion-exchange process on hydrous tetratitanate. Compounds with the formula $\mathrm{Na}_{x} \mathrm{H}_{2-x} \mathrm{Ti}_{4} \mathrm{O}_{9} \cdot 3.3 \mathrm{H}_{2} \mathrm{O}$ had an interlayer distance of $11.2 \AA$. The partially dehydrated form, $\mathrm{NaHTi}_{4} \mathrm{O}_{9} \cdot \mathrm{H}_{2} \mathrm{O}$, had an interlayer distance of $8.4 \AA$. The latter decomposed into a mixture of phases of sodium hexatitanate $\left(\mathrm{Na}_{2} \mathrm{Ti}_{6} \mathrm{O}_{13}\right)$ and anatase after heat treatment at $873 \mathrm{~K}$. Since our samples have a $d$ spacing of $9.8 \AA$, it is suspected that interlayer water molecules are more than 1 but less than 3 per formula. Furthermore, because layered titanates contain oxygen atoms of low coordination numbers (10), infrared spectra shall show Ti-O stretching at higher frequencies than that from anatase or rutile. Indeed, Fig. 4 shows that the IR spectra of the synthesized oxides have a rather sharp peak at $906 \mathrm{~cm}^{-1}$ near the Ti-O stretching band, which becomes negligible after the layered structure is collapsed through calcination.

The $\mathrm{NH}_{4}^{+}$tetratitanate is believed to release $\mathrm{NH}_{3}$ on heating and transform to $\mathrm{H}_{2} \mathrm{Ti}_{4} \mathrm{O}_{9}$ at rather low temperatures. The thermal decomposition of the latter compound has been well characterized by Izawa et al. ( $/ I)$. The reaction was proposed to be a dehydration reaction followed by phase transfer in the sequence of

$$
\begin{array}{r}
\mathrm{H}_{2} \mathrm{Ti}_{4} \mathrm{O}_{9} \underset{-\mathrm{H}_{2} \mathrm{O}}{\stackrel{523 \mathrm{~K}}{\longrightarrow}} \mathrm{H}_{2} \mathrm{Ti}_{8} \mathrm{O}_{17} \stackrel{<773 \mathrm{~K}}{\longrightarrow} \mathrm{TiO}_{2}(\mathrm{~B}) \\
\stackrel{\mathrm{H}_{2} \mathrm{O}}{\mathrm{773-1073 \textrm {K }}} \mathrm{TiO}_{2} \text { (anatase) }
\end{array}
$$

where $\mathrm{TiO}_{2}(\mathrm{~B})$ has the same host lattice as that of $\mathrm{Na}_{x} \mathrm{TiO}_{2}$ bronze. Since the anatase phase was observed after the synthetic bimetallic oxides were calcined at $623 \mathrm{~K}$, the phase transition processes on our samples seemed to occur at temperatures lower than that reported by Izawa et al. Furthermore, $\mathrm{Cr}$ (III) was considered to be incorporated into the lattice of anatase structure, especially when the $\mathrm{Cr} / \mathrm{Ti}$ ratios were low. The lattice, however, was destabilized by Cr(III) substitution for Ti(IV) because the crystallinity decreased with the increase in $\mathrm{Cr}$ (III) content and a separate $\mathrm{Cr}_{2} \mathrm{O}_{3}$ phase was formed for samples of high $\mathrm{Cr}$ (III) content.

The BET surface areas of the synthesized oxides are tabulated in Table 1. Calcination caused the surface areas to shrink from ca. $200 \mathrm{~m}^{2} / \mathrm{g}$ to ca. $110 \mathrm{~m}^{2} / \mathrm{g}$ at $623 \mathrm{~K}$, and to less than $75 \mathrm{~m}^{2} / \mathrm{g}$ at $723 \mathrm{~K}$. On the other hand, the surface areas are larger for samples of higher $\mathrm{Cr}$ (III) content. These phenomena can be correlated with the variation in crystallinity.

TABLE 1

BET Surface Areas of the Catalysts after $\mathrm{NH}_{4}^{+} / \mathrm{Na}^{+}$ Ion Exchange

\begin{tabular}{rcrcc}
\hline $\begin{array}{c}\mathrm{Cr} /(\mathrm{Ti}+\mathrm{Cr}) \\
(\%)\end{array}$ & \multicolumn{3}{c}{ BET surface area $\left(\mathrm{m}^{2} / \mathrm{g}\right)$} \\
\cline { 2 - 5 } & $\begin{array}{c}\text { Before } \\
\text { calcination }\end{array}$ & \multicolumn{3}{c}{ Calcination } \\
\cline { 3 - 5 } & & $623 \mathrm{~K}$ & $723 \mathrm{~K}$ & $943 \mathrm{~K}$ \\
\hline 0 & 256 & 95 & 65 & 58 \\
1 & 185 & 106 & - & 32 \\
5 & 187 & 118 & 43 & 50 \\
9 & 195 & 117 & 71 & 65 \\
20 & 218 & 166 & 75 & 70 \\
100 & - & 54 & 42 & - \\
\hline
\end{tabular}


TABLE 2

Kinetic Data of 2-Propanol Decomposition over Cr-Ti Oxides ${ }^{a}$

\begin{tabular}{|c|c|c|c|c|c|c|}
\hline \multirow{2}{*}{$\begin{array}{c}\mathrm{Cr} /(\mathrm{Ti}+\mathrm{Cr}) \\
(\%)\end{array}$} & \multicolumn{4}{|c|}{$R_{\mathrm{p}} / R_{\mathrm{a}}\left(\mathrm{cm}^{3} / \mathrm{g} \cdot \mathrm{min}\right)$} & \multirow{2}{*}{$\begin{array}{c}E_{\mathrm{a}_{\mathrm{p}}} \\
(\mathrm{kcal} / \mathrm{mol})\end{array}$} & \multirow{2}{*}{$\begin{array}{c}E_{\mathrm{a}_{\mathrm{a}}} \\
(\mathrm{kcal} / \mathrm{mol})\end{array}$} \\
\hline & $493 \mathrm{~K}$ & $\begin{array}{l}523 \mathrm{~K} \\
\left(\mathrm{~cm}^{3} / \mathrm{s}\right.\end{array}$ & $\cdot \begin{array}{c}553 \mathrm{~K} \\
\cdot \min )\end{array}$ & $583 \mathrm{~K}$ & & \\
\hline 0 & $0.42 /-$ & $1.83 / 0.15$ & $13.3 / 0.74$ & $48.0 / 1.97$ & 30.4 & 26.5 \\
\hline 1 & - & $0.25 / 0.21$ & $1.76 / 1.26$ & $13.4 / 5.70$ & 40.2 & 33.4 \\
\hline 5 & $0.26 / 0.56$ & $0.78 / 1.55$ & $5.67 / 7.89$ & $33.0 / 27.3$ & 31.4 & 25.2 \\
\hline 9 & $0.35 / 1.06$ & $1.36 / 3.40$ & $16.7 / 12.4$ & $88.6 / 48.7$ & 36.2 & 24.2 \\
\hline 20 & $0.26 / 1.64$ & $1.71 / 5.42$ & $9.72 / 14.2$ & $65.3 / 42.8$ & 34.9 & 20.6 \\
\hline 100 & $3.07 / 7.72$ & $15.4 / 21.2$ & $31.8 / 29.4$ & $89.3 / 70.4$ & 21.2 & 13.5 \\
\hline
\end{tabular}

${ }^{a} R_{\mathrm{p}}=$ rate of propylene formation; $R_{\mathrm{a}}=$ rate of acetone formation; $E_{\mathrm{a} p}=$ activation energy of propylene formation; $E_{\mathrm{a}_{2}}=$ activation energy of acetone formation.

Both propylene and acetone were obtained as products when 2-propanol was decomposed over the synthesized oxides. This implies that the oxides contain both acidic and basic sites. The kinetic data were analyzed according to first-order kinetics in a plug-flow reactor. Table 2 lists the calculated rate constants for the formation of propylene and acetone, respectively, over the samples of various $\mathrm{Cr}$ (III) content after calcination at $623 \mathrm{~K}$. Among them, pure chromium oxide demonstrated the highest activities in both dehydrogenation and dehydration reactions. On the other hand, pure titanium oxide shows fair activity in dehydration reaction, but the lowest activity in dehydrogenation reaction. Moreover, the selectivity to propylene was found to be affected by the Cr(III) content, as illustrated in Fig. 5. The products contained more than $92 \%$ ethylene over pure titanium oxide. The value dropped sharply when a very small quantity of $\mathrm{Cr}$ (III) was doped into the catalyst. Therefore, it is proposed that the basic sites are associated with Cr(III) ions, which substitute for Ti(IV) ions in the anatase lattice.

The surface acid strength of the mixed oxides was determined by temperature-programmed desorption of ammonium (Fig. 6). The $\mathrm{NH}_{3}$ molecules desorbed at temperatures lower than $473 \mathrm{~K}$ are considered due to physical adsorption on the surface. Pure titanium oxide shows another desorption maximum at $558 \mathrm{~K}$. Pure chromium oxide has a maximum at $638 \mathrm{~K}$. While the sample with $1 \% \mathrm{Cr}$ (III) has only one maximum at $493 \mathrm{~K}$, the rest of the $\mathrm{Cr} / \mathrm{Ti}$ bimetallic oxides show two maxima: one at ca. 493-513 $\mathrm{K}$ and the other at ca. 573-583 K. Accordingly, pure chromium oxide has the strongest acidic sites and the sample with $1 \%$ $\mathrm{Cr}$ (III) has the weakest acidic sites. The activation energies calculated for 2-propanol dehydration reaction (Table 2 ) were found to vary in a similar trend.

Infrared spectra in the $\mathrm{O}-\mathrm{H}$ stretching region of the calcined samples are illus-

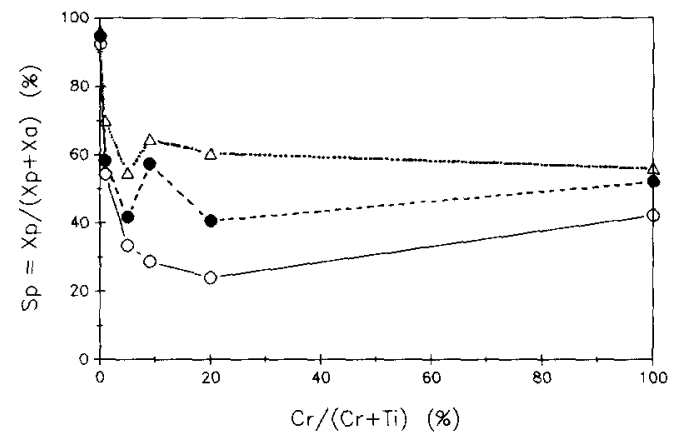

Frg. 5. Selectivities of propylene over total conversion in 2-propanol decomposition reaction over $\mathrm{Cr}-\mathrm{Ti}$ oxides as a function of $\mathrm{Cr} /(\mathrm{Ti}+\mathrm{Cr})$ ratio. $\mathrm{O}, 523 \mathrm{~K}$; $553 \mathrm{~K} ; \triangle, 583 \mathrm{~K}$. 


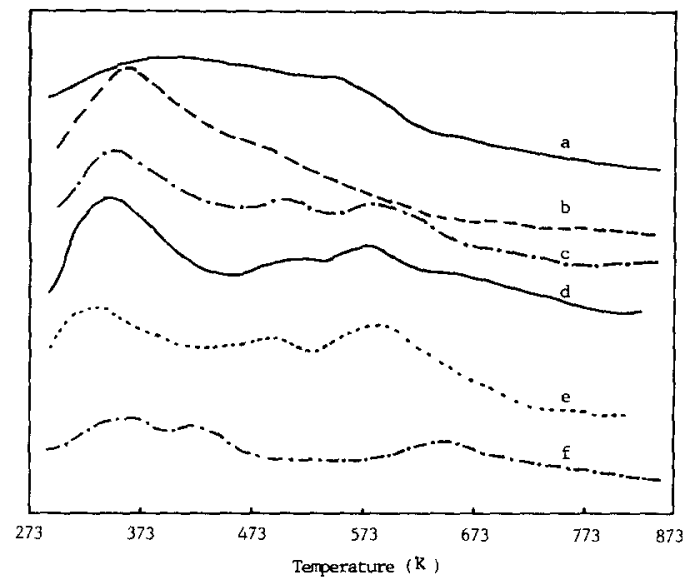

FIG. 6. Temperature-programmed desorption profiles of $\mathrm{NH}_{3}$ over $\mathrm{Cr}-\mathrm{Ti}$ oxides. $\mathrm{Cr} /(\mathrm{Ti}+\mathrm{Cr})$ ratios varied as (a) $0 \%$, (b) $1 \%$, (c) $5 \%$, (d) $9 \%$, (e) $20 \%$, and (f) $100 \%$.

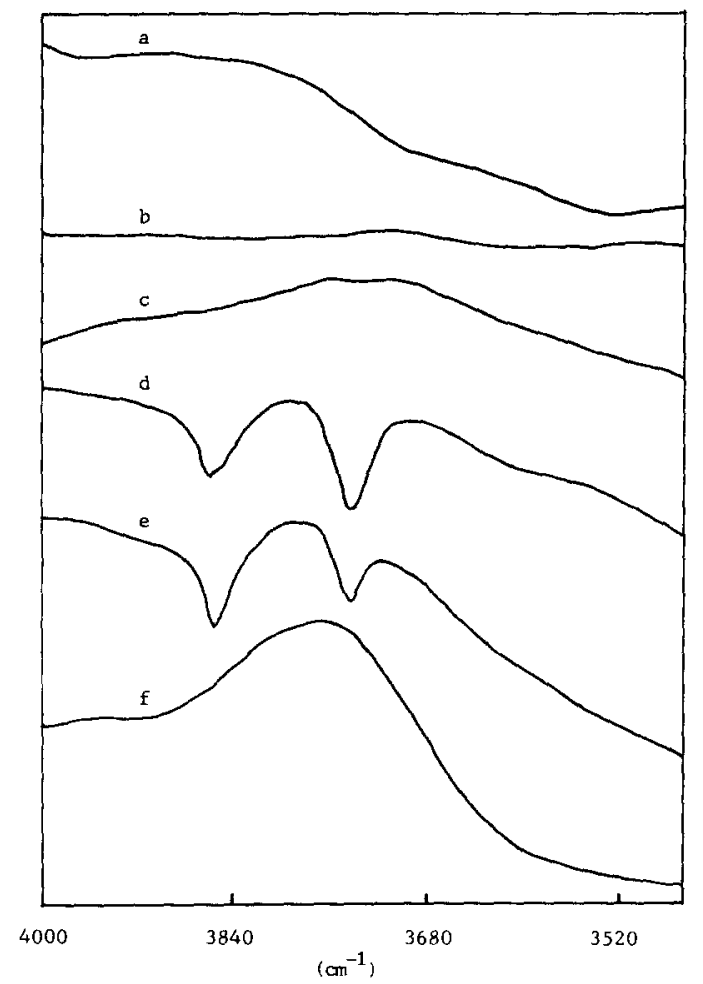

FIG. 7. FT-IR spectra of Cr-Ti oxide wafers after evacuation at $623 \mathrm{~K}$ for $1 \mathrm{~h}$. $\mathrm{Cr} /(\mathrm{Ti}+\mathrm{Cr})$ ratios varied as (a) $0 \%$, (b) $1 \%$, (c) $5 \%$, (d) $9 \%$, (e) $20 \%$, and (f) $100 \%$. trated in Fig. 7. Two peaks were observed at 3749 and $3855 \mathrm{~cm}^{-1}$, respectively, on the samples of $\mathrm{Cr}(\mathrm{III})$ content 9 and $20 \%$. The rest of the samples showed negligible absorption in this region. Judging from the charge density of the lattice cations, the peak at $3749 \mathrm{~cm}^{-1}$ is assigned to $\mathrm{TiO}-\mathrm{H}$ stretching and $3855 \mathrm{~cm}^{-1}$ to $\mathrm{CrO}-\mathrm{H}$ stretching. Parkyns summarized the IR frequencies of surface hydroxyl groups on titania reported by several authors (13). TiO-H stretching frequencies ranged from 3668 to $3740 \mathrm{~cm}^{-1}$ depending on the heat treatment and the crystalline phases. The values are close to the $3749 \mathrm{~cm}^{-1}$ observed on our samples. On heating to $723 \mathrm{~K}$ and $943 \mathrm{~K}$, the peak at $3855 \mathrm{~cm}^{-1}$ became weaker while that at $3749 \mathrm{~cm}^{-1}$ was retained (Fig. 8). To study the nature of the acid sites, infrared spectra of pyridine adsorbed on the surface of the mixed oxides were examined. Figure $9 \mathrm{~A}$ is the spectra of the sample with $9 \%$ $\mathrm{Cr}$ (III) after calcination at $623 \mathrm{~K}$. There were peaks at $1440,1443,1477,1492,1553$, 1578, 1596, and $1604 \mathrm{~cm}^{-1}$ comprising the vibrational modes of pyridine. Among them, peaks at 1443, 1492, 1578, and 1596

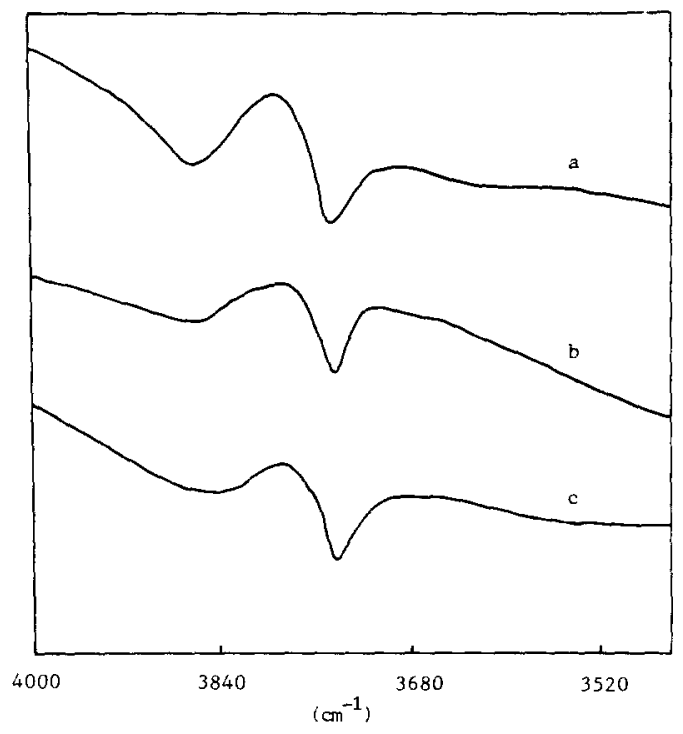

FIG. 8. FT-IR spectra of $\mathrm{Cr}$ - Ti oxides with $\mathrm{Cr} /(\mathrm{Ti}+$ Cr) ratio of $9 \%$ after evacuation at (a) $623 \mathrm{~K}$, (b) $723 \mathrm{~K}$, and (c) $943 \mathrm{~K}$. 

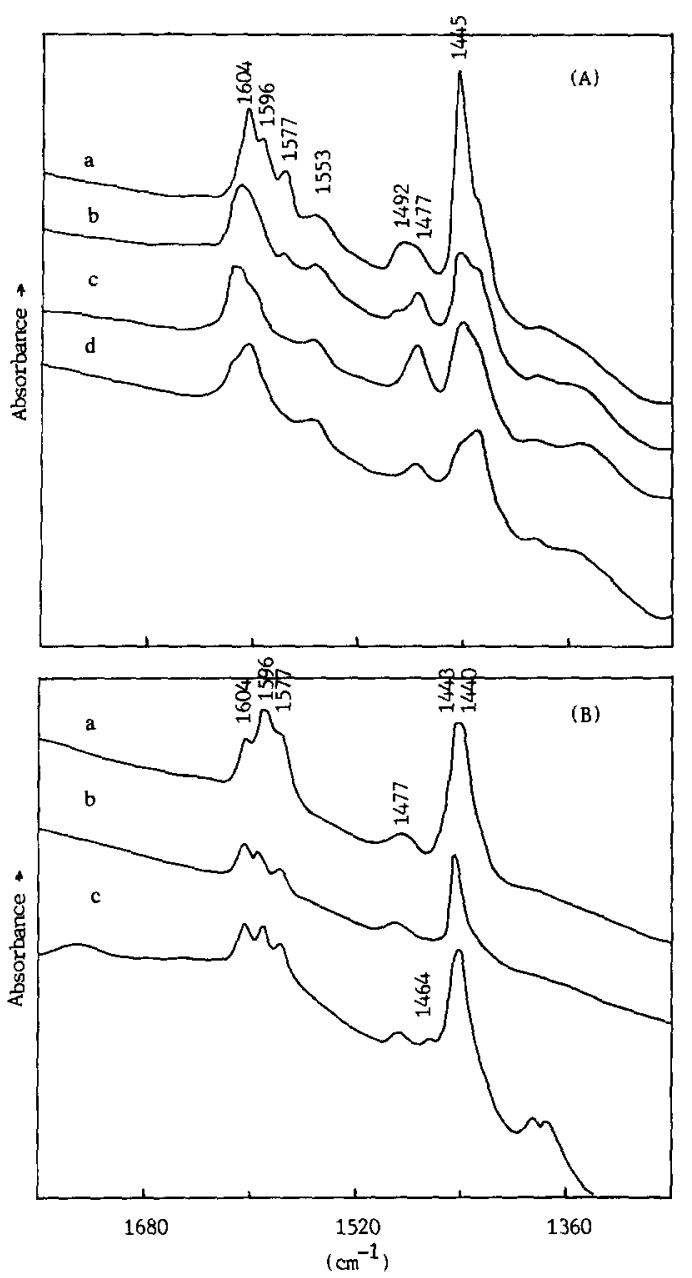

FIG. 9. FT-IR spectra of pyridine adsorbed on calcined $\mathrm{Cr}-\mathrm{Ti}$ oxide $(\mathrm{Cr} /(\mathrm{Ti}+\mathrm{Cr})=9 \%)$ after evacuation at (a) RT (b) $423 \mathrm{~K}$, (c) $523 \mathrm{~K}$, and (d) $623 \mathrm{~K}$. The calcination temperatures were (A) $623 \mathrm{~K}$ and (B) 723 K.

$\mathrm{cm}^{-1}$ were weakened after evacuation at $423 \mathrm{~K}$, and almost disappeared after evacuation at $523 \mathrm{~K}$. According to Kung and Kung (14), this set of absorption peaks can be assigned to hydrogen-bonded pyridine. On the other hand, a new peak appeared at $1613 \mathrm{~cm}^{-1}$ on heating. That and the rest of peaks survived even at an evacuation temperature of $623 \mathrm{~K}$. Connell and Dumesic (15) indicated that peaks at 1553 and 1613 $\mathrm{cm}^{-1}$ were the characteristic peaks of pyridinium ions, which were formed on the Brønsted acid sites. The other set of ab- sorption peaks at 1440,1477 , and $1604 \mathrm{~cm}^{-1}$ was contributed by pyridine coordinatively bonded to Lewis acid sites. Figure 9B shows the IR spectra of pyridine adsorbed on the same sample calcined at $723 \mathrm{~K}$. Peaks attributed to hydrogen-bonded pyridine at 1443, 1492, 1577, and $1596 \mathrm{~cm}^{-1}$ were observed in addition to those from Lewis acid sites at 1440, 1477, and 1604 $\mathrm{cm}^{-1}$. We conclude that both Brønsted and the Lewis acid sites exist on the surface of the bimetallic oxides after calcination at 623 $K$, but the bimetallic oxides lose the Brønsted acid sites after calcination at 723 $\mathrm{K}$. TiO-H groups are still observed on the latter compounds, which implies that the TiO-H groups do not contribute to the Brønsted acidity. In other words, the Bronsted acid sites are the $\mathrm{CrO}-\mathrm{H}$ groups.

Figure 10 demonstrates the redox activi-

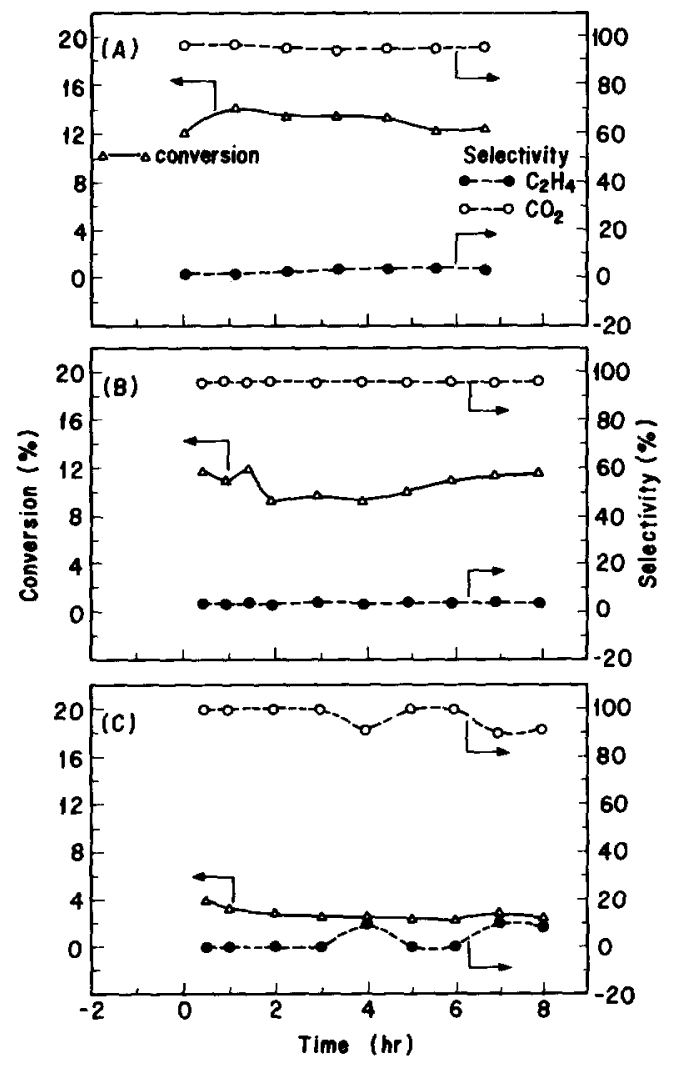

FIg. 10. Activities of $\mathrm{Cr}-\mathrm{Ti}$ oxides in ethane oxidative dehydrogenation reaction. Catalysts had $\mathrm{Cr} /(\mathrm{Ti}+$ Cr) ratios of (a) $100 \%$, (b) $20 \%$, and (c) $5 \%$. 
ties of the bimetallic oxides in the oxidative dehydrogenation of ethane. Besides the desired product, ethylene, carbon dioxide was obtained as a major product through complete oxidation of ethane or ethylene. The conversion was found to be proportional to the $\mathrm{Cr}$ content of the oxides. Pure chromium oxide gave the highest activity. The total conversion of ethane was ca. 14 mol\%. However, only 4 mol\% of the products was ethylene. On the other hand, the selectivity of ethylene was found to be independent of $\mathrm{Cr}$ content. It is therefore proposed that the active sites for the formation of ethylene and $\mathrm{CO}_{2}$ are the same and may have to do with surface $\mathrm{Cr}-\mathrm{O}$ species. Ti(IV) served more as a diluent.

\section{CONCLUSIONS}

$\mathrm{Cr}$ (III)/Ti(IV) bimetallic oxides prepared by the hydrothermal method in basic solution were found to have layered structures. After $\mathrm{NH}_{4}^{+} / \mathrm{Na}^{+}$ion exchange and calcination, the tetratitanate was converted to anatase-form $\mathrm{TiO}_{2}$ structure. $\mathrm{Cr}(\mathrm{III})$ ions were proposed to substitute for the Ti(IV) ions in the lattice. As a result, the crystallinity of the anatase phase decreased with the increase in $\mathrm{Cr}$ (III) content. A separate $\mathrm{Cr}_{2} \mathrm{O}_{3}$ phase was also observed on samples of high $\mathrm{Cr}$ (III) content. Over pure titanium oxide, propylene was the predominant product obtained in the 2-propanol decomposition reaction. Selectivity decreased sharply when a very small quantity of $\mathrm{Cr}$ (III) was doped into the oxide. Since both propylene and acetone were obtained in the products, it was concluded that the synthetic bimetallic oxides contain both acidic and basic sites. Furthermore, there were two kinds of acid sites on the bimetallic oxides-Brønsted and Lewis. The Brønsted acid sites were determined to be the $\mathrm{CrO}-\mathrm{H}$ groups on the surface. The $\mathrm{Cr}-\mathrm{O}$ species were also proposed to be the active sites for the oxidative dehydrogenation of ethane to ethylene and for complete oxidation to $\mathrm{CO}_{2}$.

\section{ACKNOWLEDGMENT}

Financial support from the National Science Council of the Republic of China is gratefully acknowledged.

\section{REFERENCES}

1. Tauster, S. J., Fung, S. C., and Garden, R. L., J. Amer. Chem. Soc. 100, 170 (1978).

2. Matsuda, S., Takeuchi, M., Hishinuma, T., Nakajima, F., Narita, T., Watanabe, Y., and Imanati, M., J. Air Pollut. Control Assoc. 28, 350 (1978).

3. Inomata, M., Miyamoto, A., and Murakami, Y., J. Chem. Soc. Chem. Commun., 223 (1980).

4. Matsuda, S., and Kato, A., Appl. Catal. 8, 149 (1983).

5. Shibata, K., Kitagawa, T., Sumiyoshi, T., and Tanabe, K., Bull. Chem. Soc. Japan 46, 2985 (1973)

6. Tanabe, K., Sumiyoshi, T., Shibata, K., Kiyoura, T., and Kitagawa, J., Bull. Chem. Soc. Japan 47, 106 (1974).

7. Gbelica, Z., Derouane, E. G., and Blom, N., in "Catalytic Materials," Chap. 12. Amer. Chem. Soc., Washington, DC, 1984.

8. Cheng, S., and Lee, J.-C., J. Chin. Chem. Soc. 35, 191 (1988).

9. Marchand, R., and Brohan, L., Mater. Res. Bull. 15, 1129 (1980).

10. Izawa, H., Kikkawa, S., and Koizumi, M., Polyhedron 2, 741 (1983).

11. Izawa, H., Kikkawa, S., and Koizumi, M., $J$. Phys. Chem. 86, 5023 (1982).

12. Sasaki, T., Watanabe, M., and Fujiki, Y., Bull. Chem. Soc. Japan 58, 3500 (1985).

13. Parkyns, N. A., in "Chemisorption and Catalysis' (P. Hepple, Ed.). Elsevier, Amsterdam, 1970.

14. Kung, M. C., and Kung, H. H., Catal. Rev.-Sci. Eng. 3, 425 (1985).

15. Connell, G., and Dumesic, J. A., J. Catal. 105, 285 (1987). 